\title{
A Different 'Spin' on Rhenium Chemistry. Synthetic Approaches and Perspectives of 17-Electron Rhenium Complexes
}

\author{
Fabio Zobi
}

\begin{abstract}
Transition metal complexes of rhenium and technetium find wide application in nuclear medicine and the chemistry of these elements is still the focus of intense research efforts. For therapeutic and diagnostic applications, currently much attention is dedicated to the development of new targeting strategies aimed at appending the metal complexes to biological vectors (e.g. a peptide) for a site-specific delivery of the radionuclides. Advancements in radiopharmacy, however, will not only arise from the development of new targeted strategies but also from the exploration of the chemistry of these elements in their unusual oxidation states. In this respect the even number oxidation states of Re and Tc (i.e. $+I I,+I V$ and $+\mathrm{VI}$ ) are relatively poorly understood. In particular, stable and substitutionally labile mononuclear 17 -electron species of the elements $\left(+I I, d^{5}\right)$ are a rarely encountered class of complexes. In this review we present our recent developments in the field of rhenium (II) chemistry with emphasis on the novel synthetic strategies we have recently introduced. We will also describe how the unique chemical and electronic properties of $\operatorname{Re}(॥)$-based complexes may provide a potentially new approach for applications in inorganic medicinal chemistry.
\end{abstract}

Keywords: Biomolecules · 17-Electron complexes · Labeling · Rhenium · Synthon

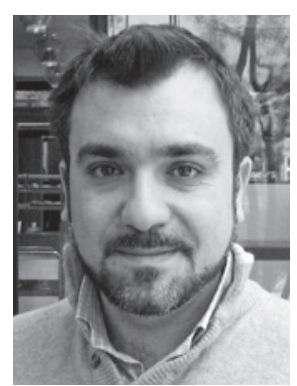

Fabio Zobi was born in Italy in 1976 and studied chemistry at the York University (Toronto, Canada) where in 2001 he received a Master degree working in the group of Prof. Dennis V. Stynes. He then moved to Zurich where in 2005 he obtained his PhD under the direction of Prof. Roger Alberto. After spending nearly two years as postdoctoral fellow in the group of Peter J. Sadler at the University of Edinburgh he moved back to Zurich. Since 2009 he is an independent researcher holding a SNF-Ambizione fellowship. Fabio Zobi's research interests are diverse covering different topics in inorganic and medicinal chemistry.

\footnotetext{
${ }^{\star}$ Correspondence: Dr. F. Zobi

University of Zurich

Institute of Inorganic Chemistry

Winterthurerstrasse 190

$\mathrm{CH}-8057$ Zurich

Tel.: +411635 4623

Fax: + 4116356802

E-mail: fzobi@aci.uzh.ch
}

\section{Introduction}

Rhenium (II) chemistry is rare due to the inaccessibility of versatile $\operatorname{Re}(\mathrm{II})$ precursors as starting materials. The same is true to an even larger extent for technetium (II). This contrasts with manganese (II) which is probably the best investigated oxidation state for this element. The lack of $\operatorname{Re}(\mathrm{II})$ and $\mathrm{Tc}$ (II) is surprising since their complexes would be 17- (or 19) electron compounds, electronically unsaturated species with potentially useful and fundamentally interesting properties. For many other elements, the search for 17-electron complexes is a focus and has resulted in promising compounds in inorganic medicinal chemistry (e.g. NAMI-A) ${ }^{[1,2]}$ catalysis or magnetic materials.

The recently published 'Comprehensive Coordination Chemistry' book dedicates a total of just four pages (including figures) to $\operatorname{Re}(\mathrm{II})$ chemistry. ${ }^{[3]}$ This is due to the fact that since 1987 less than one publication every two years has appeared on the subject. The complexes reported were sometimes obtained as an expected product (or by-product) from chemical procedures intended for the synthesis of Re compounds in formal oxidation states other than +II. ${ }^{[4]}$ Thus, fewer than 50 articles comprise the entire literature of $\operatorname{Re}(\mathrm{II})$ chemistry and these can be further reduced to 15 fundamental reports. ${ }^{[5-20]}$ The rhenium chemistry of this oxidation state is dominated by phosphorus ligands. A few notable exceptions are complexes of binding ligands such aromatic amines or isocyanides. ${ }^{[12,14]}$ The main routes for the synthesis of $\operatorname{Re}(\mathrm{II})$ compounds involve oxidation of $\operatorname{Re}(\mathrm{I})$ or the reduction of $\operatorname{Re}(\mathrm{III})$ complexes. Additionally, examples are known where $\operatorname{Re}($ II) species are formed via the cleavage of $\mathrm{Re}-$ $\mathrm{Re}$ bonds of bimetallic units such as $\left[\operatorname{Re}_{2}\left(\mathrm{NCCH}_{3}\right)_{10}\right]^{4+} .[5,6,21,22]$

Clearly, little research is actively pursued on Re(II) complexes due to the lack of stable but substitutionally labile $\operatorname{Re}(\mathrm{II})$ precursors (synthons). However, compounds of the metal in its $\mathrm{d}^{5}$ configuration are attractive from the point of view of medicinal inorganic chemistry and as precursors for single-molecule magnetic clusters. There are no examples in the literature of $\operatorname{Re}(\mathrm{II})$ compounds applied in the field of inorganic medicinal chemistry. We believe this ensues from a fundamental lack of knowledge of synthetic procedures that allow one to move away from bulky lipophilic phosphine ligands that severely limit water solubility of the complexes. There are, on the other hand, many examples of Re compounds (and their Tc analogues) in formal oxidation states ranging from + I to + VII (with the exception of $+\mathrm{II}$ ) which find application particularly in radiopharmacy. The isotopes ${ }^{186} \operatorname{Re}\left(\beta^{-}\right.$emitter, $T_{1 / 2}=89.25 \mathrm{~h}$, $\left.E_{\text {max }}=1.1 \mathrm{MeV}\right)$ and ${ }^{188} \operatorname{Re}\left(\beta^{-}\right.$emitter, $T_{1 / 2}$ $=16.98 \mathrm{~h}, E_{\max }=2.1 \mathrm{MeV}$ ) for example, have physical properties that make them attractive for the radiotherapeutic treatment of cancer. Particular attention has 
been paid to ${ }^{188} \mathrm{Re}$ which can be obtained from an isotope generator system from ${ }^{188} \mathrm{~W}\left(T_{1 / 2}=69 \mathrm{~d}\right) .{ }^{[23,24]}$

In contrast to inorganic medicinal chemistry, paramagnetic rhenium complexes have received some attention in the design of single-molecule magnets (SMM). ${ }^{[19,25-28]}$ Here a brief diversion is here needed for a broader perspective. About 20 years ago, the molecular cluster $\left[\mathrm{Mn}_{12} \mathrm{O}_{12}\left(\mathrm{CH}_{3} \mathrm{CO}_{2}\right)_{16}\left(\mathrm{H}_{2} \mathrm{O}\right)_{4}\right]$ was discovered to exhibit slow magnetic relaxation at low temperatures. ${ }^{[29-31]}$ This unusual behavior is attributed to the presence of a high-spin ground state of $S=$ 10 combined with an axial magnetic anisotropy of $D=-0.5 \mathrm{~cm}^{-1}$. The possibility of utilizing such magnetic clusters for data storage applications has attracted the interests of many research groups. However, progress in this area has only been incremental. The main difficulty, which remains a great challenge for the physical chemists, is that it is hard to predict and control the sign and magnitude of $D$. To achieve the desired anisotropy one idea is to move down the periodic table and utilize complexes of second- and thirdrow transition-metal ions, for which the greater spin-orbit coupling increases the magnitude of the zero-field splitting. The rhenium ion is particularly suited for this purpose due to: i) a large degree of spin delocalization of its complexes onto the ligands ${ }^{[32]}$ and ii) its remarkable magnetic anisotropy due to the high value of the spin-orbit coupling parameter. ${ }^{[33]}$

The strategy of utilizing second- and third-row transition-metal ions in the construction of SMM has been recently and successfully applied for the synthesis of Mo(III)-based cyanide clusters ${ }^{[34,35]}$ and in one case, for the preparation of a family of mixed-metal cyanide cubes containing octahedral $\operatorname{Re}(\mathrm{II})$ vertices. ${ }^{27,28,36]} \operatorname{Re}(\mathrm{II})$ complexes, thus, appear as potentially useful building blocks for SMM. However, one of the problems of generating $\operatorname{Re}(\mathrm{II})$ clusters is the lack of a synthetic strategy that allows one to produce $\operatorname{Re}(\mathrm{II})$ precursors in a systematic manner. It has been experimentally demonstrated that supramolecular chemistry based on $\operatorname{Re}(\mathrm{II})$ precursors is a powerful entry into the design of molecular materials with tunable magnetic, electronic and photophysical properties. ${ }^{[27,28,36]}$ However, this research requires a steady influx of new precursors and the study of both discrete molecules and their polymeric architecture. It is this fundamental problem that our research wants to tackle.

In this contribution, we discuss some of our recent developments in the field of rhenium (II) chemistry with particular emphasis on the novel synthetic strategies we have recently introduced. We have cho- sen to focus on this subject because only a systematic understanding of the basic reactivity and the fundamental electronic properties of $\operatorname{Re}(\mathrm{II})$-based building blocks will allow any further development and application of this $\mathrm{d}^{5}$ metal ion in the field of inorganic medicinal chemistry and magnetic materials. As will be evident to the reader, we are only at the very beginning of understanding this fascinating chemistry.

\section{The cis- $\left[\mathrm{Re}^{\prime \prime} \mathrm{Br}_{4}(\mathrm{CO})_{2}\right]^{2-}$ Complex: A True Synthon}

One of the first synthetic approaches to $\operatorname{Re}(\mathrm{II})$ complexes we explored in our laboratory is based on a 1-electron reduction of the air stable $\left(\mathrm{Et}_{4} \mathrm{~N}\right)\left[\mathrm{Re}^{\mathrm{III}} \mathrm{Br}_{4}(\mathrm{CO})_{2}\right]$ (1) salt. This salt was reported about 15 years ago by Abram et al. but has received no attention and to date its chemistry remains largely underdeveloped. [37] Only recently $\mathbf{1}$ was used as a precursor for the synthesis of $\operatorname{Re}(\mathrm{I})$ complexes comprising the $c i s-\left[\operatorname{Re}^{\mathrm{I}}(\mathrm{CO})_{2}\right]^{+}$core via a straightforward two-electron reduction by tetrakisdimethylaminoethylene (TDAE). ${ }^{[38,39]}$ Since direct two-electron transfer reactions are rare, we reasoned that it was likely that a $\operatorname{Re}(\mathrm{II})$ complex would form as an intermediate in the reaction. Indeed, by carefully controlling the stoichiometry of the reaction we were able to access the analytically pure $\left(\mathrm{Et}_{4} \mathrm{~N}\right)_{2}\left[\mathrm{Re}^{\mathrm{II}} \mathrm{Br}_{4}(\mathrm{CO})_{2}\right]$ (2) salt (Scheme 1). ${ }^{[40]}$

As a solid complex $\mathbf{2}$ is stable in air, it can be solubilized in a range of polar organic solvents and it does not decompose if kept under anaerobic conditions. In solution the coordinated halides readily exchange for other ligands or coordinating solvents. Thus, for example, when $\mathbf{2}$ is dissolved in methanol, the complex $\left[\mathrm{Re}^{\mathrm{II}}(\mathrm{CO})_{2}\left(\mathrm{HOCH}_{3}\right)_{4}\right]^{2+}$ is formed. This behavior parallels that of $\left[\operatorname{Re}^{\mathrm{I}} \mathrm{Br}_{3}(\mathrm{CO})_{3}\right]^{2-}$ (a well known species widely investigated in inorganic and nuclear medicine chemistry) and underlines the presence of a fully solvated species useful as a synthon for subsequent $\operatorname{Re}($ II) chemistry.

Owing to the rapid exchange of at least one $\mathrm{Br}^{-}$by coordinating solvent molecules, $\mathbf{2}$ could not be structurally characterized so far but the mono-nuclearity of $\mathbf{2}$ was assessed by magnetic measurements. The low spin $\mathrm{d}^{5}$ electronic configuration was confirmed in the range between 5 and $300 \mathrm{~K}$. At low temperature $(5 \mathrm{~K})$, compound 2 exhibits a $\mu_{\text {eff }}=1.77$ B.M. as expected for a $\mathrm{d}^{5}$ system with one single unpaired electron ( $\mu=1.73$ B.M.) and it shows an EPR spectrum strongly anisotropic with $g$ values between 3 and 1.7.[40]

As outlined in the introduction, $\operatorname{Re}(\mathrm{II})$ complexes are generally prepared by

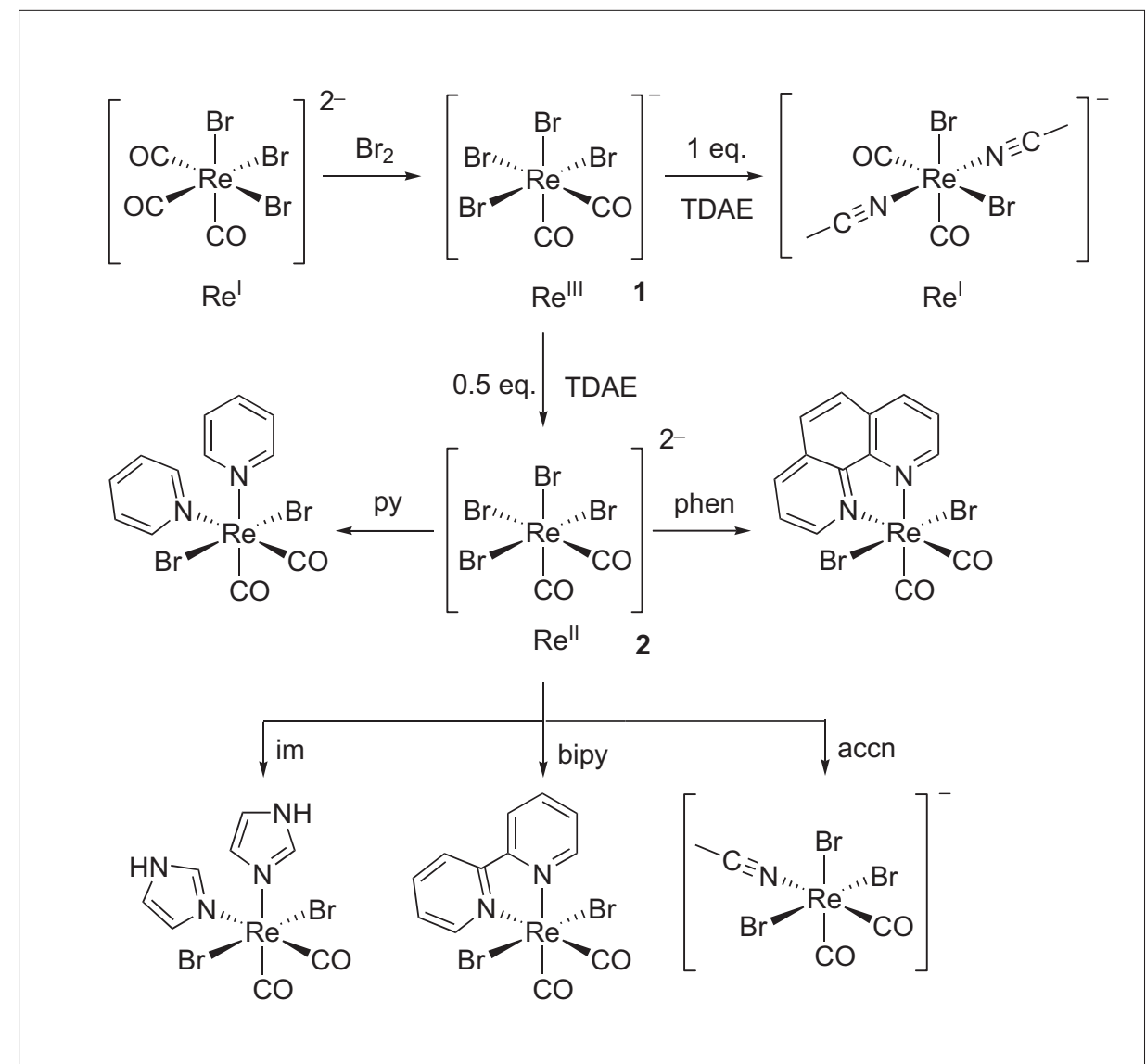

Scheme 1. Synthesis and selected substitution reactions of the Re(II) synthon 2. 
redox reactions either from the corresponding $\operatorname{Re}(\mathrm{I})$ or $\operatorname{Re}(\mathrm{III})$ complexes. This is especially true for coordination compounds ${ }^{[41-45]}$ but corresponding investigations with organometallic complexes are rare. There are no examples in the literature of a common mononuclear $\operatorname{Re}(\mathrm{II})$ precursor from which different species may be synthesized. Thus, we originally probed if one could access $\operatorname{Re}(\mathrm{II})$ complexes in a concerted reduction/ligand substitution reaction of $\mathbf{1}$ by reducing the salt with TDAE in the presence of excess of different ligands. The concerted reduction/coordination reaction does occur but this approach is very limited with respect to ligand types.

The difficulties and limitations in the reduction/coordination process, however, can be immediately eliminated by starting from the synthon 2 . Thus the direct reaction of $\mathbf{2}$ with different monodentate (L) or bidentate $(\mathrm{N} \cap \mathrm{N})$ ligands gives in short time and in good isolated yield the corresponding $\left[\mathrm{Re}^{\mathrm{II}} \mathrm{Br}_{2}(\mathrm{~L})_{2}(\mathrm{CO})_{2}\right]$ or $\left[\mathrm{Re}^{\mathrm{II}} \mathrm{Br}_{2}(\mathrm{~N} \cap \mathrm{N})(\mathrm{CO})_{2}\right]$ complexes (Scheme 1). ${ }^{[40]}$ These simple ligand substitution reactions are a rare feature for a mononuclear 17-electron rhenium complex. It is surprising for example that $\mathbf{2}$ lacks the tendency to form a Re-Re metal bond.

We found $\mathbf{2}$ to react well specially with pyridine- and imidazole-type ligands but substitution reactions are not limited to aromatic amine ligands and may extend to a wide variety of complexes with other ligand types of interest in e.g. catalysis. It is interesting to note that all complexes thus far derived from $\mathbf{2}$ are stable in solution even under aerobic conditions. If exposed to $\mathrm{O}_{2}$ the UV/Vis spectra of the compounds do not change over a period of two days. Concomitantly, if monitored by electrochemical techniques during the same period of time, the fully reversible one-electron process referred to the $\operatorname{Re}(\mathrm{II})$ $\rightarrow \operatorname{Re}(\mathrm{I})$ reduction of the complexes shows no appreciable loss of intensity. ${ }^{[40]}$

All the properties of $\mathbf{2}$ (and its derived compounds) underline the importance of this labile synthon for the preparation of a wide variety of paramagnetic mononuclear 17-electron Re(II) complexes. In its relevance, this synthon will certainly stimulate $\operatorname{Re}(\mathrm{II})$ chemistry which is largely underdeveloped in comparison to the other oxidation states of this element. The unexpected aerobic stability and well behaved chemistry of complexes derived from 2 implies reactions leading to novel complexes relevant for applications in medicinal chemistry and magnetic materials for which the compounds may be utilized as building blocks for paramagnetic clusters for e.g. single molecule magnets (SMM).

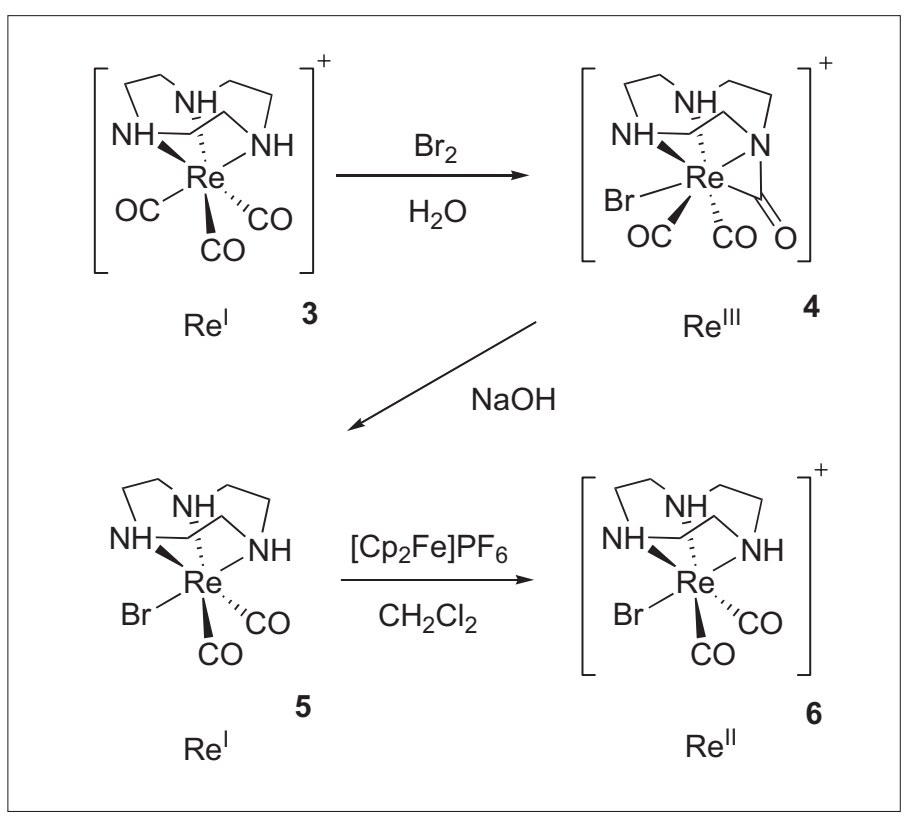

Scheme 2.

Ligand-Mediated

Decarbonylation (LMD)

scheme leading to \{cis$\left.\left.\operatorname{Re}^{\prime}(\mathrm{CO})_{2}\right]^{+}\right\}$and $\{$cis-

$\left.\left.\mathrm{Re}^{\prime \prime}(\mathrm{CO})_{2}\right]^{2+}\right\}$ complexes with 1,4,7-triazacyclononane (tacn) as the reaction supporting tridentate ligand.

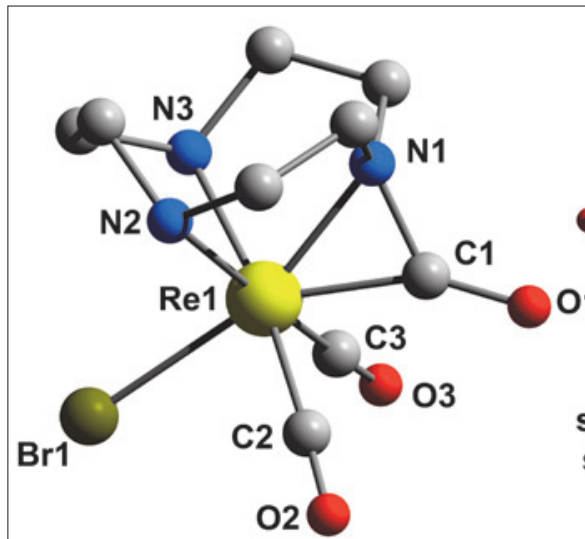

Fig. 1. Structural representation of complex 4. The drawing to the right shows the square pyramidal scaffold for the decarbonylation (LMD) reaction.

\section{Ligand-Mediated Decarbonylation (LMD) Reaction}

A second synthetic approach we have explored to $\operatorname{Re}(\mathrm{II})$ complexes is based on what we now call the 'ligand-mediated decarbonylation (LMD) reaction' ${ }^{[46,47]}$ The full synthetic LMD scheme is shown in Scheme 2 with 1,4,7-triaza-cyclononane (tacn) as the tridentate ligand. This procedure was developed over a few months and it began with the observation that addition of $\mathrm{Br}_{2}$ at room temperature to an aqueous solution of complex $\mathbf{3}$ afforded a yellow microcrystalline solid within $30 \mathrm{~min}$ in good yield. When $\mathbf{4}$ was finally structurally characterized we realized that it consisted of a seven-coordinate $\operatorname{Re}(\mathrm{III})$ complex comprising an unusual three-membered ring acyl amide bond. Indeed, prior to its structural elucidation and based on IR data, the structure of $\mathbf{4}$ was anticipated as a carboxycarbonyl complex of the type trans-[(tacn) $\left.\operatorname{Re}^{\text {III }}(\mathrm{CO}){ }_{2} \mathrm{Br}(\mathrm{COOH})\right]$ which is more common in $\operatorname{Re}(\mathrm{III})$ chemistry. ${ }^{[48-50]}$

Because of its unusual three-membered ring acyl amide bond, the chemistry of 4 was the subject of further investigation, ${ }^{[46]}$ but relevant to this discussion is a brief description of the structure of the complex (Fig. 1). With the exception of the angles encompassing $\mathrm{N}(1)$ and $\mathrm{C}(1)$, all angles around the metal coordination sphere differ only slightly from $90^{\circ}$. On average $\mathrm{L}(1)-\operatorname{Re}(1)-\mathrm{L}(2)$ angles (where $\mathrm{L}(1)$ and L(2) are coordinated atoms) are $89.0^{\circ}(4)$. Thus, with the exclusion of $\mathrm{C}(1)$ and $\mathrm{N}(1)$ the remaining five ligands may be considered as forming a square pyramidal scaffold for the decarbonylation reaction (Fig. 1).

The fundamental decarbonylation reaction of $\mathbf{4}$, which is at the core of the LMD procedure, may be initiated by $[\mathrm{OH}]^{-}$ions. In this step the hydroxide ion acts as a nucleophile displacing the acyl amide bond generating a carbamic acid intermediate prior to $\mathrm{CO}_{2}$ release and formation of the $\operatorname{Re}(\mathrm{I})$ complex 5 in quantitative yield. The LMD of $\mathbf{4}$ has been studied in detail via theoretical calculations at the density functional level of theory (Fig. 2). ${ }^{446]} \mathrm{We}$ found that the $\left[\mathrm{Re}^{\mathrm{III}} \mathrm{Br}(\operatorname{tacn})\right.$ $\left.(\mathrm{CO})_{3}\right]^{2+}$ complex (7) is the likely first 


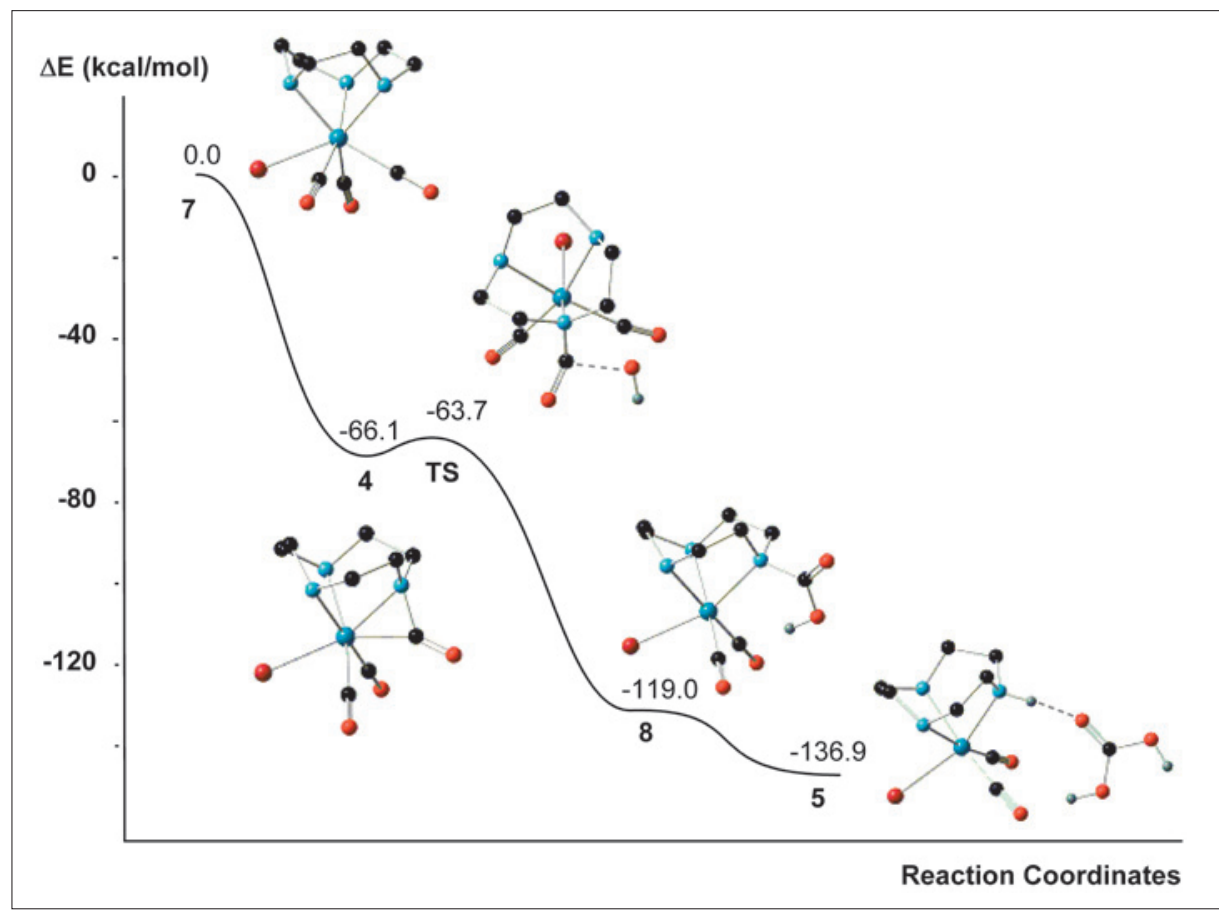

Fig. 2. Potential energy surface for the calculated reaction mechanism leading to $\mathbf{5}$. Energies are in $\mathrm{kcal} / \mathrm{mol}$ and relative to the ground-state reactants.

product of the $2 \mathrm{e}^{-}$oxidation of $\mathbf{3}$ by $\mathrm{Br}_{2}$. This type of $\mathrm{Re}^{\mathrm{III}}$ or $\mathrm{Tc} \mathrm{c}^{\mathrm{III}}$ cation was also identified and characterized in oxidative bromination reactions of cyclopentadienyl complexes such as fac- $\left[\mathrm{Re}^{\mathrm{I}}\left(\mathrm{C}_{5}\left(\mathrm{CH}_{3}\right)_{5}\right)\right.$
$\left.(\mathrm{CO})_{3}\right]$ and also found in similar reactions of rhenacarboranes species. ${ }^{[51-53]}$ After formation of 7 , the presence in solution of $[\mathrm{OH}]^{-}$close to the tacn ligand leads to $\mathrm{NH}$ deprotonation. The hydrogen migra- tion from nitrogen to oxygen caused the elimination of a water molecule and a rearrangement leading to the mono-cationic species $\mathbf{4}$, characterized by the formation of the three-membered ring acyl amide bond.

In a subsequent step the presence of the $[\mathrm{OH}]^{-}$ion in the vicinity of the tacn ligand leads to an attack of $[\mathrm{OH}]^{-}$on the $\mathrm{N}$-coordinated carbonyl carbon atom of 4, yielding the neutral carbaminic acid intermediate 8, formulated as [(tacn)-N$\left.\left(\mathrm{CO}_{2} \mathrm{H}\right) \operatorname{Re}(\mathrm{CO})_{2} \mathrm{Br}\right]$. The last step of the decarbonylation required an attack of $[\mathrm{OH}]^{-}$onto the carboxylate carbon which weakens the $\mathrm{N}-\mathrm{C}$ bond. Simultaneously, the carbaminic nitrogen abstracts one proton from water. The calculated pathway to the formation of $\mathbf{5}$ was found to be highly favored, both energetically and kinetically (Fig. 2). ${ }^{[46]}$

The LMD of $\mathbf{4}$ has a remarkable effect on the electronic properties of the Re centre. While 3 cannot be oxidized up to a potential of $+1.2 \mathrm{~V}, \mathbf{5}$ showed a fully reversible one-electron oxidation wave centered around $+0.20 \mathrm{~V}$. This observation allowed us to synthesize [(tacn) $\mathrm{Re}^{\mathrm{II}}(\mathrm{CO})_{2} \mathrm{Br}_{\mathrm{P}} \mathrm{PF}_{6}(6)$ in quantitative yield from the reaction of $\mathbf{5}$ with ferrocenium hexafluorophosphate $\left(\left[\mathrm{Cp}_{2} \mathrm{Fe}\right] \mathrm{PF}_{6}\right)$. The LMD reaction and the subsequent chemi-
Scheme 3. Redoxswitch activity of 6: Coordination of a substrate (accn in $\mathrm{A}$ and $9 \mathrm{Me}-\mathrm{G}$ in B) turns the switch 'on' since the redox potentials of the resulting complexes $\mathbf{9}^{+}$and $10^{+}$are strongly increased. Subsequent $1 \mathrm{e}^{-}$ reduction results in the highly robust $\mathrm{Re}^{\mathrm{l}}$ complexes $\mathbf{9}$ and $\mathbf{1 0}$ By 'OFF/ON position' it is indicated the tendency of the $\operatorname{Re}($ II) complex to be reduced back to a d $d^{6}$ low spin $\operatorname{Re}(\mathrm{l})$ system. 


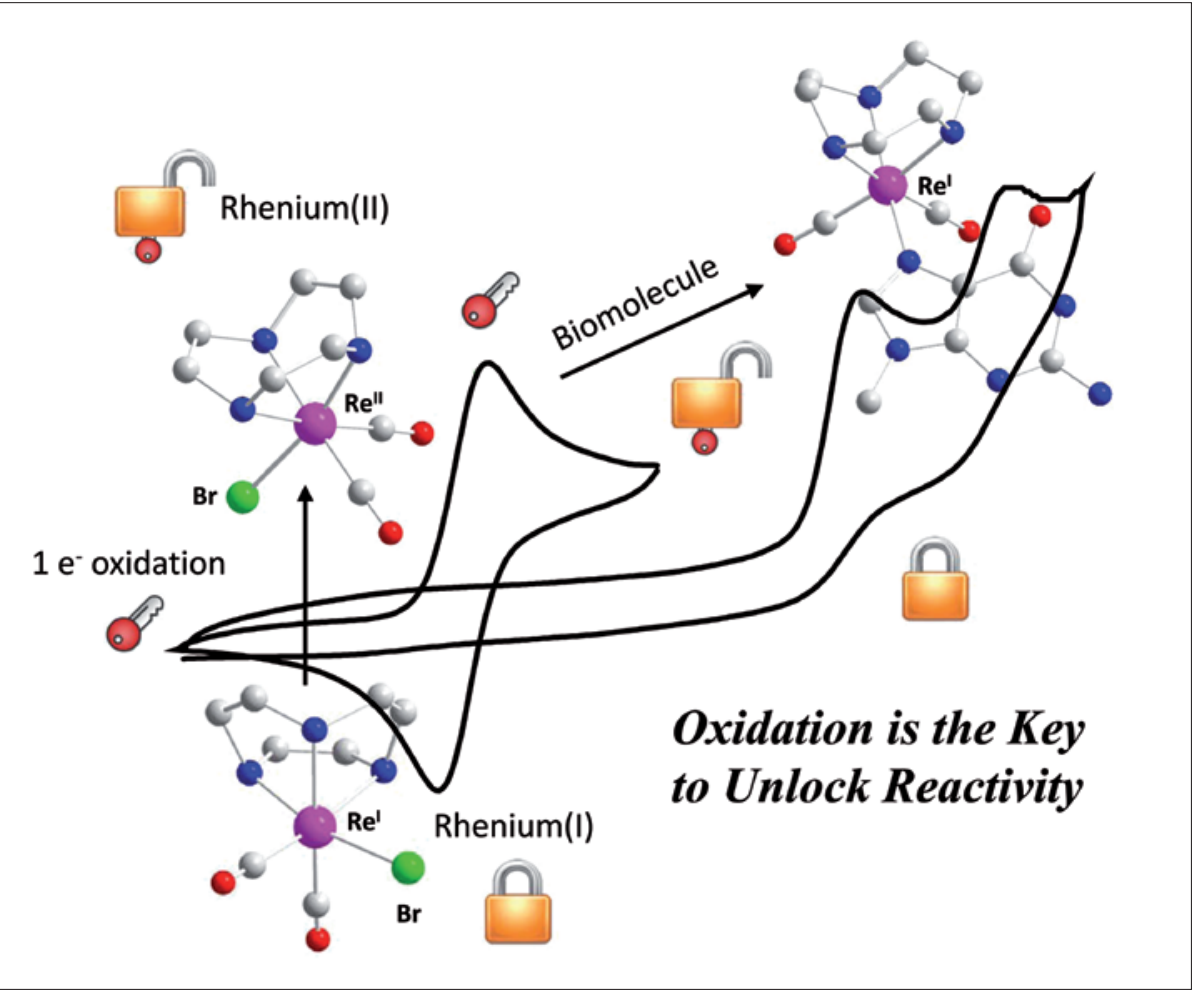

Fig. 3. An illustration of the 'redox-switch' concept. Rhenium (I) dicarbonyl complexes are inert or 'locked' towards ligand substitution. A one-electron oxidation to corresponding $\operatorname{Re}(॥)$ complexes provides the key to 'unlock' the reactivity of the compounds. Ligand substitution alters the electronic properties of the Re(II) centre which is reduced back to a d ${ }^{6}$ low spin $\operatorname{Re}($ I) system whose reactivity is once again 'locked'. cal oxidation of $\operatorname{Re}(\mathrm{I}) \rightarrow \operatorname{Re}(\mathrm{II})$ herein described represents a convenient and general route to amine complexes of the $\left\{\right.$ cis- $\left.\left[\operatorname{Re}(\mathrm{CO})_{2}\right]^{2+}\right\}$ core.${ }^{[46,47]}$

\section{The Redox-Switch and Labeling of Biomolecules.}

Complexes of the type $\left[\left(\mathrm{L}^{3}\right) \operatorname{Re}^{\mathrm{I}}(\mathrm{CO})_{3}\right]$ are only oxidized at high potentials since ciently through $\pi$-back donation. The potentials change substantially if one CO is replaced by a donor ligand. As we have described above, $\left[\operatorname{Re}^{\mathrm{I}} \mathrm{Br}(\operatorname{tacn})(\mathrm{CO})_{2}\right]$ (5) shows a fully reversible one-electron oxidation at moderate $\mathrm{E}_{1 / 2}=+0.20 \mathrm{~V}$ vs. $\mathrm{Ag} /$ $\mathrm{AgCl}$ whereas $\left[\operatorname{Re}^{\mathrm{I}}(\operatorname{tacn})(\mathrm{CO})_{3}\right]^{+}$could not be oxidized up to $+1.2 \mathrm{~V}$. This different electrochemical behavior mirrors the distinctly different electronic properties of rhenium after replacing $\mathrm{CO}$ for the $\sigma$-donor $\mathrm{Br}^{-}$. It is this remarkable electronic difference that allowed us to access 17-electron rhenium complexes of the $\left\{\right.$ cis- $\left.\left[\operatorname{Re}(\mathrm{CO})_{2}\right]^{2+}\right\}$ core via LMD.

During the course of our investigation we noticed that when oxidizing $\mathbf{5}$ with $\left[\mathrm{Cp}_{2} \mathrm{Fe}\right] \mathrm{PF}_{6}\left(\mathrm{Fc}^{+}\right)$in acetonitrile (accn), the $\left[\operatorname{Re}^{\mathrm{I}}(\operatorname{tacn})(\operatorname{acc})(\mathrm{CO})_{2}\right] \mathrm{PF}_{6}\left(\mathbf{9}\left[\mathrm{PF}_{6}\right]\right)$ complex formed exclusively. The color of the reaction mixture changed from bluegreen $\left(\mathrm{Fc}^{+}\right)$to orange (ferrocene, $\mathrm{Fc}$ ) and the three CO ligands stabilize Re(I) effi-
$\left.(\mathrm{CO})_{2}\right]^{2+}\left(\mathbf{9}^{+}\right)$. This substitution turned the redox-switch 'on'. The Re $\mathrm{R}^{\mathrm{II}}$ complex $\mathbf{9}^{+}$is a strong oxidant $\left(\mathrm{E}_{1 / 2}=+0.78 \mathrm{~V}\right.$ for $\operatorname{Re}(\mathrm{I})$ $\mathrm{Fc}$ back to $\mathrm{Fc}^{+}$whilst being reduced to $\left[\operatorname{Re}^{\mathrm{I}}(\operatorname{tacn})(\operatorname{accn})(\mathrm{CO})_{2}\right]^{+}(\mathbf{9})$ (Scheme 3). In the net reaction, $\mathrm{Br}^{-}$in $\mathbf{5}$ has simply been replaced by accn to give 9 . However, since dissolution of $\mathbf{5}$ in accn did not lead to even traces of $\mathbf{9}$, the conversion described above is not a simple $\mathrm{Br}^{-} \rightarrow$ $\mathrm{NCCH}_{3}$ substitution reaction.

This observation allowed us to develop what we refer to as the 'redoxswitch' concept for labeling biomolecules (Scheme 3 and Fig. 3). ${ }^{[54]}$ Briefly, rhenium (I) dicarbonyl complexes obtained via LMD exhibit very slow kinetics for ligand exchange as expected for a $\mathrm{d}^{6}$ low spin $\operatorname{Re}(\mathrm{I})$ system. Such complexes may be considered inert or 'locked' towards ligand substitution. Under physiological conditions, for example (i.e. DMSO/ $\mathrm{H}_{2} \mathrm{O}$ mixture, $37{ }^{\circ} \mathrm{C}$, neutral $\mathrm{pH}$ ) the coordinated bromide ion in $\mathbf{5}$ can neither be replaced by stronger $\sigma$-donors ligands like imidazole or cyanide nor exchanged with soft donors like thiols. ${ }^{[4]}$ The one-electron oxidation of these species, however, generates the corresponding $\operatorname{Re}(\mathrm{II})$ complexes which are substitutionally labile. In this sense the one-electron oxidation process may be considered the key to 'unlock' the reactivity of the compounds. In their $\mathrm{d}^{5}$ spin state the rhenium complexes are 'unlocked' but in an 'off' position as long as the halide is the primary coordination sphere of the metal ion. Once the halide is substituted, however (i.e. as in the case with accn described above for $\mathbf{5}$ ), the electronic properties of the rhenium $\rightarrow \operatorname{Re}(\mathrm{II})$, vs. $\mathrm{Ag} / \mathrm{AgCl})$ and converted

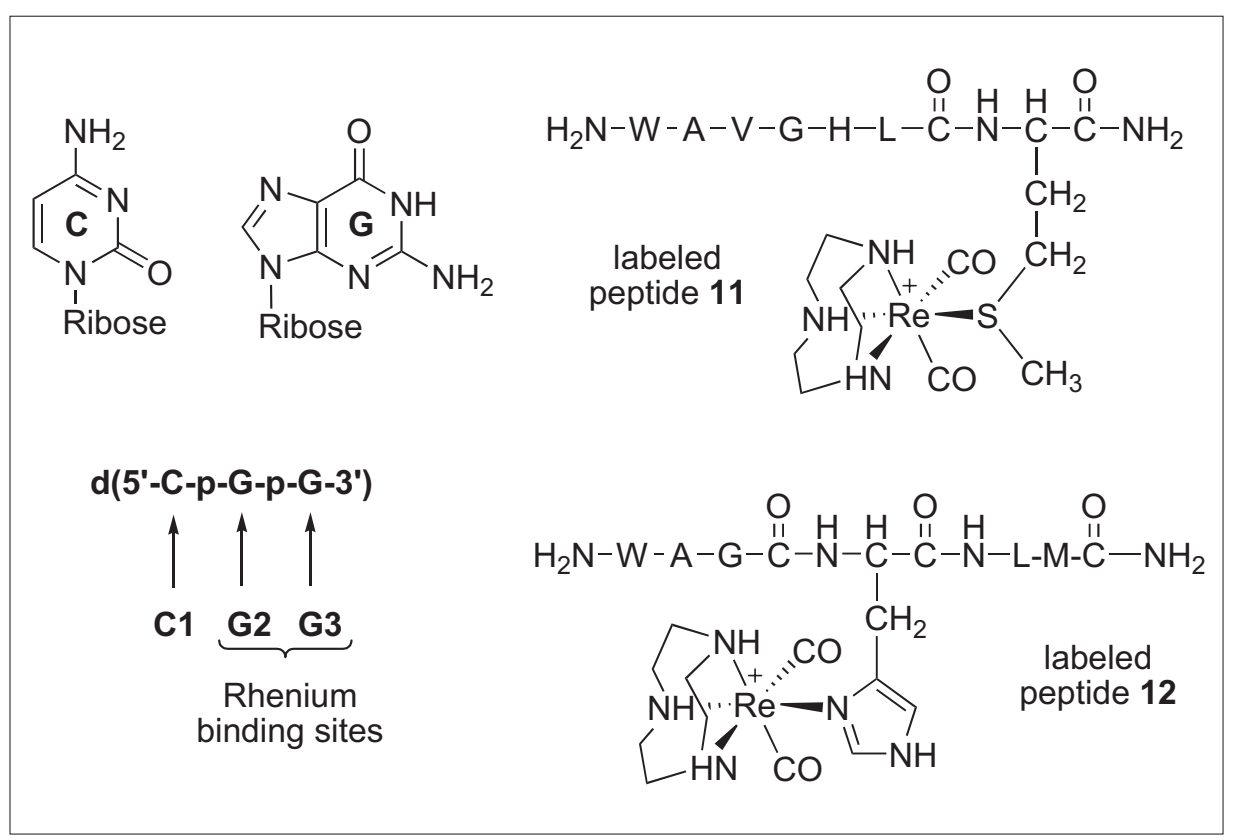

Scheme 4. Reaction products of $\mathrm{d}\left(5^{\prime}-\mathrm{CpGpG}-3^{\prime}\right)$ and $\mathrm{H}_{2} \mathrm{~N}-\mathrm{W}-\mathrm{A}-\mathrm{V}-\mathrm{G}-\mathrm{H}-\mathrm{L}-\mathrm{M}-\mathrm{CONH} \mathrm{H}_{2}$ respectively with $\left[\operatorname{Re} e^{\prime \prime} \operatorname{Br}(\operatorname{tacn})(\mathrm{CO})_{2}\right]^{+}(6)$ in water. 


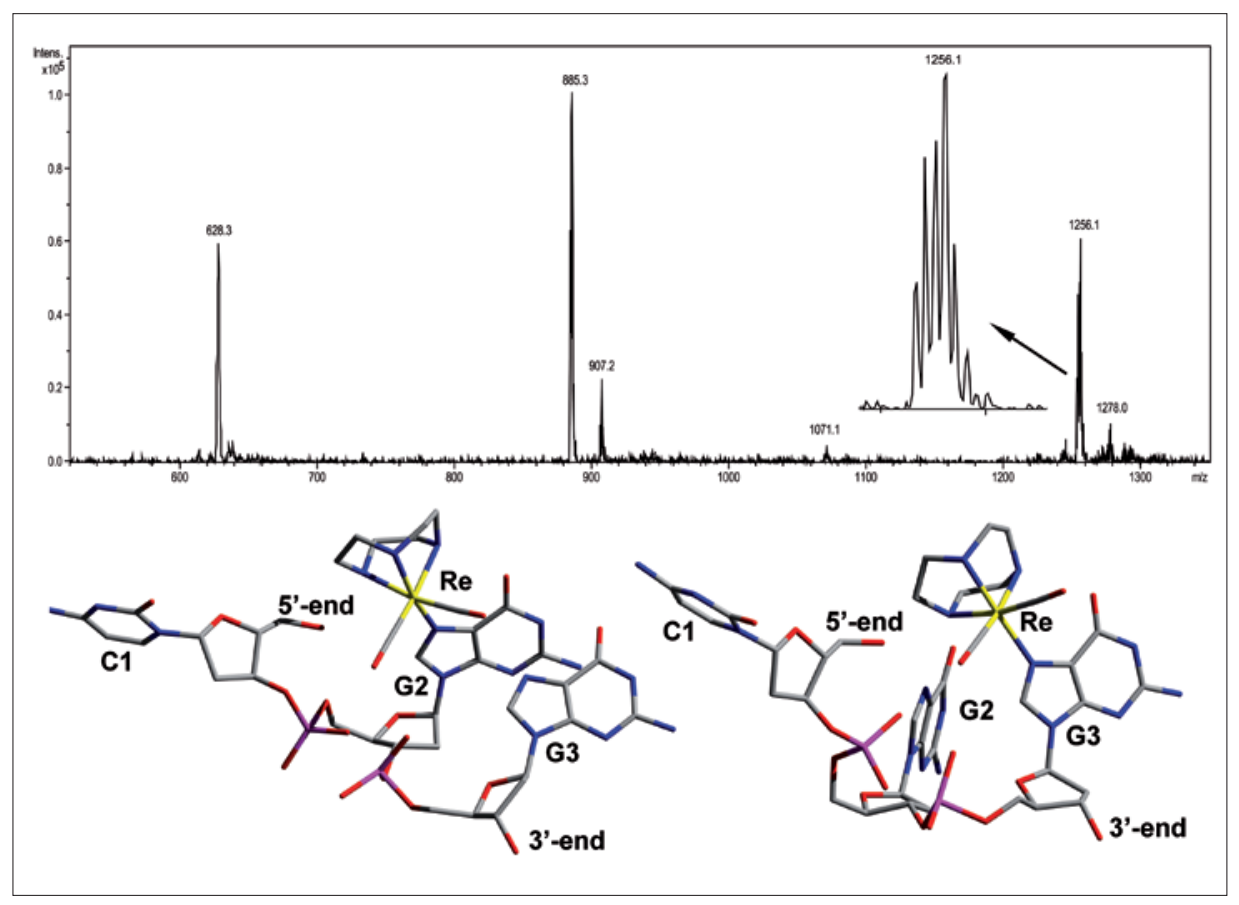

Fig. 4. MS spectrum of the labelled oligonucleotide $d\left(5^{\prime}-C p G p G-3^{\prime}\right)$ and DFT optimized structures of the two adducts formed.

centre are greatly altered and the metal ion moves to an 'on' position in terms of the tendency of the $\operatorname{Re}$ (II) complex to be reduced back to a $\mathrm{d}^{6}$ low spin $\operatorname{Re}(\mathrm{I})$ system. This last step generates a new robust and inert $\operatorname{Re}(\mathrm{I})$ complex whose reactivity is once again 'locked' and where the metal ion reverts back to an 'off' position.

We probed if the induction of a strong oxidation potential upon coordination to a target and subsequent reduction to a robust [Re ${ }^{\mathrm{I}}$-substrate] complex (i.e. the redoxswitch) could be used as a new strategy for the labeling of biomolecules. We have studied in this respect the reactions of $\mathbf{6}$ with DNA bases, a small oligonucleotide sequence $d\left(5^{\prime}-\mathrm{CpGpG}-3^{\prime}\right)$ and the peptide $\mathrm{H}_{2} \mathrm{~N}-\mathrm{W}-\mathrm{A}-\mathrm{V}-\mathrm{G}-\mathrm{H}-\mathrm{L}-\mathrm{M}-\mathrm{CONH}_{2} \cdot{ }^{[54]}$ In all cases we found the expected $\left[\mathrm{Re}^{\mathrm{I}}-\right.$ substrate] complexes. The reaction of $\mathbf{6}$ with 9-methylguanine (9-Me-G), for example, gave $\left[\operatorname{Re}^{\mathrm{I}}(\operatorname{tacn})(9 \mathrm{Me}-\mathrm{G})(\mathrm{CO})_{2}\right] \mathrm{PF}_{6}$ (10 $\left[\mathrm{PF}_{6}\right]$ ) (Scheme 3). The redox potential

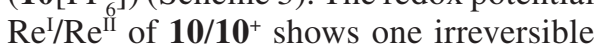
wave at $\mathrm{E}_{1 / 2}=+0.81 \mathrm{~V}$. The only difference in 6 and $\mathbf{1 0}^{+}$is one ligand, bromide (6) instead of guanine $\left(\mathbf{1 0}^{+}\right)$. The $600 \mathrm{mV}$ difference between the two complexes caused by the substitution demonstrates the redox-switch concept (Fig. 3).

Complex $\mathbf{1 0}$ is very robust in aqueous solution. No decomposition or ligand substitution was observed over days, hence, metallation of guanine is essentially irreversible. Similarly the reaction in water of 6 with $\mathrm{d}\left(5^{\prime}-\mathrm{CpGpG}-3^{\prime}\right)$ yields two products corresponding to the coordination of rhenium to G2 and one to G3 (Scheme 4 and Fig. 4). ${ }^{[54]}$ The induction of reduction by coordination was also found for other potentially coordinating groups in biomolecules. The reaction of $\mathbf{6}$ with the peptide $\mathrm{H}_{2} \mathrm{~N}-\mathrm{W}-\mathrm{A}-\mathrm{V}-\mathrm{G}-\mathrm{H}-\mathrm{L}-\mathrm{M}-\mathrm{CONH}_{2}$ in water at r.t. and under slightly acidic conditions gave the labeled peptide $\mathbf{1 1}$ as the major product (Scheme 4). At neutral $\mathrm{pH}$, coordination to histidine (labeled peptide 12) was also detected but methionine remained the preferred binding site. ${ }^{[54]}$

In all the labeling reactions described above, the $\operatorname{Re}^{\mathrm{II}} \rightarrow \mathrm{Re}^{\mathrm{I}}$ reduction occurred after coordination of $\mathbf{6}$ since the $\operatorname{Re}(\mathrm{I})$ complex 5 did not at all undergo $\mathrm{Br}^{-}$substitution by histidine, methionine or guanine. The redox reaction leading to irreversible labeling provoked the question about the reducing agent. For the reaction with $9 \mathrm{Me}-\mathrm{G}$, histidine or the peptide, we speculate that the only reducing agent is $\mathrm{Br}^{-}$itself. This is a question which still remains to be answered and the detailed mechanism of these reactions is currently a subject of our research. Nevertheless, the redox-switch concept exemplifies how the unique chemical and electronic properties of $\operatorname{Re}(\mathrm{II})$-based complexes represent a potentially new strategy for applications in inorganic medicinal chemistry.

\section{Concluding Remarks and Perspectives}

In this contribution we have discussed some basic aspects of the chemistry of recently introduced rhenium (II) building blocks. Although this research is only making its first steps, we believe that a systematic understanding of the basic reactivity and the fundamental electronic properties of $\mathrm{d}^{5} \mathrm{Re}$ (and $\mathrm{Tc}$ ) complexes will have an impact not only in the field of basic rhenium chemistry but also in application-oriented processes. The chemistry herein presented, for example, might serve as a base for the synthesis of new radiopharmaceuticals. The possibility of ligand-induced fine-tuning of the complexes combined with their unique electrochemical properties (i.e. as unsaturated $17 \mathrm{e}^{-}$species) may permit their use in catalysis or in the design of data storage devices.

The systematic synthetic pathways to Re(II) complexes should allow a steady influx of possible new SMM precursors. Tailoring $\operatorname{Re}(\mathrm{II})$ precursors with ligands impacting systematically on the electrochemical properties of the metal will help to discriminate and understand differences in the resulting magnetic behavior of the molecules. A library of magnetic properties should then allow for some degree of control over the design of molecular materials with tunable magnetic and electronic properties for data storage applications.

The controlled design of the electrochemical properties of complexes of the Re ion in its $d^{5}$ electronic configuration and the derived data might help physical chemists to develop new models that allow some degree of prediction over the magnitude and sign of the zero-field splitting (zfs) parameter $D$. After all, zfs (i.e. the removal of spin microstate degeneracy for systems with $S>1 / 2$ in the absence of an applied field) is by definition a consequence of the molecular electronic structure and/or spin density distribution. In general the introduction of the widely applicable synthetic strategies to novel stable substitutionally labile $\operatorname{Re}(\mathrm{II})$-based building blocks will have a fundamental impact in the field of rhenium chemistry, opening new horizons in basic chemistry, technology, application and scholarship. Stable substitutionally labile $\operatorname{Re}(\mathrm{II})$ complexes will open new strategies for $e . g$. cancer therapy and the design of new SMM.

\section{Acknowledgements}

Financial support from the Swiss National Science Foundation (SNF-Ambizione PZ00P2_121989/1) is gratefully acknowledged. I am also thankful to the University of Zurich and the Institute of Inorganic Chemistry for hosting my research as well as to all the research colleagues therein. I am particularly obliged to Prof. Dr. Roger Alberto and Priv.-Doz. Dr. Bernhard Spingler.

Received: February 3, 2010

[1] C. G. Hartinger, M. A. Jakupec, S. ZorbasSeifried, M. Groessl, A. Egger, W. Berger, 
H. Zorbas, P. J. Dyson, B. K. Keppler, Chem. Biodiversity 2008, 5, 2140.

[2] C. G. Hartinger, S. Zorbas-Seifried, M. A Jakupec, B. Kynast, H. Zorbas, B. K. Keppler, J. Inorg. Biochem. 2006, 100, 891.

[3] U. Abram, 'Comprehensive Coordination Chemistry II', Ed. E. C. Constable, J. R Dilworth, Elsevier, 2005, p. 350.

[4] See e.g. B. Machura, R. Kruszynski, J. Kusz, Inorg. Chem. Comm. 2007, 10, 918.

[5] J. D. Allison, P. E. Fanwick, R. A. Walton, Organometallics 1984, 3, 1515 .

[6] M. Bakir, P. E. Fanwick, R. A. Walton, Polyhedron 1987, 6, 907.

[7] A. M. Bond, R. Colton, R. W. Gable, M. F. Mackay, J. N. Walter, Inorg. Chem. 1997, 36, 1181.

[8] A. M. Bond, R. Colton, D. G. Humphrey, P. J. Mahon, G. A. Snook, V. Tedesco, J. N. Walter, Organometallics 1998, 17, 2977.

[9] A. M. Bond, R. Colton, M. E. Mcdonald, Inorg. Chem. 1978, 17, 2842.

[10] M. F. N. N. Carvalho, M. T. Duarte, A. M Galvao, A. J. L. Pombeiro, R. Henderson, H. Fuess, I. Svoboda, J. Organomet. Chem. 1999, $583,56$.

[11] M. F. N. N. Carvalho, A. J. L. Pombeiro, U. Schubert, O. Orama, C. J. Pickett, R. L. Richards, Dalton Trans. 1985, 2079.

[12] R. M. Chin, J. Barrera, R. H. Dubois, L. E. Helberg, M. Sabat, T. Y. Bartucz, A. J. Lough, R. H. Morris, W. D. Harman, Inorg. Chem. 1997, 36, 3553.

[13] F. A. Cotton, L. M. Daniels, Inorg. Chim. Acta 1988, 142, 255.

[14] L. E. Helberg, J. Barrera, M. Sabat, W. D. Harman, Inorg. Chem. 1995, 34, 2033.

[15] L. E. Helberg, S. D. Orth, M. Sabat, W. D. Harman, Inorg. Chem. 1996, 35, 5584.

[16] K. Libson, M. Woods, J. C. Sullivan, J. W. Watkins, R. C. Elder, E. Deutsch, Inorg. Chem. 1988, 27, 999

[17] A. J. L. Pombeiro, R. L. Richards, Transition Met. Chem. 1985, 10, 463

[18] J. S. Qi, P. W. Schrier, P. E. Fanwick, R. A Walton, J. Chem. Soc., Chem. Commun. 1991, 1737.
[19] E. J. Schelter, J. K. Bera, J. Bacsa, J. R. GalanMascaros, K. R. Dunbar, Inorg. Chem. 2003, 42, 4256.

[20] M. Stebler, A. Gutierrez, A. Ludi, H. B. Burgi, Inorg. Chem. 1987, 26, 1449.

[21] C. A. Hertzer, R. E. Myers, P. Brant, R. A. Walton, Inorg. Chem. 1978, 17, 2383.

[22] T. Nimry, R. A. Walton, Inorg. Chem. 1977, 16, 2829.

[23] B. T. Hsieh, A. P. Callahan, A. L. Beets, G. Ting, F. F. Knapp, Appl. Rad. Isotop. 1996, 47, 23.

[24] F. F. Knapp, A. L. Beets, S. Guhlke, P. O. Zamora, H. Bender, H. Palmedo, H. J. Biersack, Anticancer Res. 1997, 17, 1783.

[25] D. E. Freedman, D. M. Jenkins, A. T. Iavarone, J. R. Long, J. Am. Chem. Soc. 2008, 130, 2884.

[26] J. Martinez-Lillo, D. Armentano, G. De Munno, W. Wernsdorfer, M. Julve, F. Lloret, J. Faus, J. Am. Chem. Soc. 2006, 128, 14218.

[27] E. J. Schelter, F. Karadas, C. Avendano, A. V. Prosvirin, W. Wernsdorfer, K. R. Dunbar, J. Am. Chem. Soc. 2007, 129, 8139

[28] E. J. Schelter, A. V. Prosvirin, K. R. Dunbar, J. Am. Chem. Soc. 2004, 126, 15004.

[29] A. Caneschi, D. Gatteschi, R. Sessoli, A. L. Barra, L. C. Brunel, M. Guillot, J. Am. Chem. Soc. 1991, 113, 5873.

[30] R. Sessoli, D. Gatteschi, A. Caneschi, M. A. Novak, Nature 1993, 365, 141.

[31] R. Sessoli, H. L. Tsai, A. R. Schake, S. Y. Wang, J. B. Vincent, K. Folting, D. Gatteschi, G. Christou, D. N. Hendrickson, J. Am. Chem. Soc. 1993, 115, 1804

[32] R. Gonzalez, R. Chiozzone, C. Kremer, F. Guerra, G. De Munno, F. Lloret, M. Julve, J. Faus, Inorg. Chem. 2004, 43, 3013.

[33] A. Cuevas, R. Chiozzone, C. Kremer, L. Suescun, A. Mombru, D. Armentano, G. De Munno, F. Lloret, J. Cano, J. Faus, Inorg. Chem. 2004, 43, 7823.

[34] P. A. Berseth, J. J. Sokol, M. P. Shores, J. L. Heinrich, J. R. Long, J. Am. Chem. Soc. 2000, $122,9655$.

[35] J. J. Sokol, A. G. Hee, J. R. Long, J. Am. Chem. Soc. 2002, 124, 7656.
[36] E. J. Schelter, A. V. Prosvirin, W. M. Reiff, K. R. Dunbar, Angew. Chem., Int. Ed. 2004, 43 , 4912.

[37] U. Abram, R. Hubener, R. Alberto, R. Schibli, Z. Anorg. Allg. Chem. 1996, 622, 813.

[38] L. Kromer, B. Spingler, R. Alberto, J. Organomet. Chem. 2007, 692, 1372.

[39] L. Kromer, B. Spingler, R. Alberto, Dalton Trans. 2008, 5800

[40] F. Zobi, L. Kromer, B. Spingler, R. Alberto, Inorg. Chem. 2009, 48, 8965.

[41] R. M. Chin, J. Barrera, R. H. Dubois, L. E Helberg, M. Sabat, T. Y. Bartucz, A. J. Lough, R. H. Morris, W. D. Harman, Inorg. Chem. 1997, 36, 3553 .

[42] L. E. Helberg, J. Barrera, M. Sabat, W. D. Harman, Inorg. Chem. 1995, 34, 2033.

[43] L. E. Helberg, S. D. Orth, M. Sabat, W. D. Harman, Inorg. Chem. 1996, 35, 5584.

[44] S. D. Orth, J. Barrera, M. Sabat and W. D. Harman, Abstr. Pap. Am. Chem. S. 1992, 204, INOR379.

[45] S. D. Orth, J. Barrera, M. Sabat, W. D. Harman, Inorg. Chem. 1993, 32, 594.

[46] F. Zobi, O. Blacque, G. Steyl, B. Spingler, R. Alberto, Inorg. Chem. 2009, 48, 4963.

[47] F. Zobi, B. Spingler, R. Alberto, Dalton Trans. 2008, 5287.

[48] C. F. Barrientospenna, A. B. Gilchrist, A H. Klahnoliva, A. J. L. Hanlan, D. Sutton, Organometallics 1985, 4, 478.

[49] G. Diaz, A. H. Klahn, C. Manzur, Polyhedron 1988, 7, 2743.

[50] A. H. Klahn and C. Manzur, Polyhedron 1990 9, 1131.

[51] I. Blandford, J. C. Jeffery, P. A. Jelliss, F. G. A. Stone, Organometallics 1998, 17, 1402.

[52] M. J. Fischer, P. A. Jelliss, L. M. Phifer, N. P. Rath, Inorg. Chim. Acta 2005, 358, 1531.

[53] F. Zobi, B. Spingler, R. Alberto, Eur. J. Inorg. Chem. 2008, 4205

[54] F. Zobi, R. Alberto, Chem. Eur. J. 2010, in press. 